\title{
The Basement Membrane of Intramyocardial Capillaries Is Thickened in Patients with Acute Myocardial Infarction
}

\author{
Mark P.V. Begieneman ${ }^{a, e, f} \quad$ Frank R.W. van de Goot ${ }^{a, e, f}$ Paul A.J. Krijnen ${ }^{a, e}$ \\ Jan Fritz ${ }^{a}$ Walter J. Paulus ${ }^{c, e}$ Marieke D. Spreeuwenberg ${ }^{d}$ \\ Victor W.M. van Hinsbergh ${ }^{c, e}$ Hans W.M. Niessen ${ }^{a, b, e}$ \\ Departments of a Pathology, ${ }^{b}$ Cardiac Surgery, ${ }^{\mathrm{c} P h y s i o l o g y,}{ }^{\mathrm{d}}$ Epidemiology and Biostatistics, \\ VU Medical Center, ${ }^{\mathrm{e} I C a R-V U}$, Amsterdam, and ${ }^{\mathrm{f}}$ Dutch Forensic Institute, The Hague, The Netherlands
}

\section{Key Words}

Blood vessel · Electron microscopy · Stenosis · Coronary

artery $\cdot$ Acute myocardial infarction $\cdot$ Basement

membrane $\cdot$ Capillary

\begin{abstract}
Background: Atherosclerotic epicardial coronary arteries are a major cause of acute myocardial infarction (AMI). Recently, we found that intramyocardial capillaries may also play a role in AMI induction. We have now evaluated intramyocardial capillaries using ultrastructural analysis in AMI patients. Methods: 43 AMI patients (with AMI in the left ventricle) and 27 controls. No patient included in either group had diabetes mellitus. Basement membrane (BM) thickness of intramyocardial capillaries was determined using electron microscopy. BM thickness was also studied in a rat AMI model. Results: BM thickness in the left ventricle of AMI patients was significantly higher than in controls $(102 \pm 9$ vs. $77 \pm$ $4 \mathrm{~nm} ; \mathrm{p}=0.016$ ). This increase was not found in the right ventricle. In AMI patients, BM thickness was already increased in recent infarcts and did not increase further with infarct age. No correlation was found between BM thickness and the
\end{abstract}

amount of stenosis or atherosclerotic plaque stability of epicardial coronary arteries. In addition, BM thickness did not differ between control rats and AMI rats. Conclusions: These results suggest that $B M$ thickening constitutes significant changes in the intramyocardial capillaries in patients that develop AMI. Also these changes are likely to occur prior to the induction of AMI.

Copyright $\odot 2009$ S. Karger AG, Basel

\section{Introduction}

Acute myocardial infarction (AMI), remains a leading cause of morbidity and mortality worldwide $[1,2]$. It is common knowledge that AMI is mainly caused due to alterations or abnormalities in coronary artery structure or function, especially epicardial coronary arteries, which can cause abrupt changes in regional blood flow and provoke acute ischemia [3], contributing to arrhythmia and sudden death [4-7]. AMI involving the left anterior descending coronary artery is found to be a strong determinant of increased myonecrosis, reduced left ventricular function and higher mortality, compared with infarction

\section{KARGER}

Fax +41613061234 E-Mail karger@karger.ch www.karger.com (c) 2009 S. Karger AG, Basel

$1018-1172 / 10 / 0471-0054 \$ 26.00 / 0$

Accessible online at:

www.karger.com/jvr
Dr. Mark P.V. Begieneman

VU Medical Centre

Department of Pathology, Room nr. 0E46

De Boelelaan 1117, NL-1007 HV Amsterdam (The Netherlands)

Tel. +31 20444 4003, Fax +31 20444 2964, E-Mail mpv.begieneman@vumc.nl 
Table 1. Clinical data of patients included in the study

\begin{tabular}{|c|c|c|}
\hline & Controls $(n=27)$ & Acute myocardial infarction $(n=43)$ \\
\hline Mean age (range), years & $49(24-92)$ & $55(22-83)$ \\
\hline Male/female, $\mathrm{n}$ & $15 / 12$ & $28 / 15$ \\
\hline Cause of death & $\begin{array}{l}\text { Carcinoma }(n=4), \text { DC }(n=1) \text {, intra-uterine infection }(n=1) \text {, } \\
\text { RI }(n=3) \text {, sepsis }(n=3) \text {, lung emboli }(n=1) \text {, CVA }(n=2) \text {, } \\
\text { liver cirrhosis }(n=1) \text {, myocarditis }(n=1) \text {, MOF }(n=1) \text {, } \\
\text { pneumonia }(n=3) \text {, PHT }(n=1) \text {, epileptic insult }(n=2) \text {, pre- } \\
\text { eclampsia }(n=1) \text {, arrhythmia }(n=1) \text {, aorta dissection }(n=1)\end{array}$ & $\begin{array}{l}\text { AMI }(n=42), \text { drowned after AMI } \\
(\mathrm{n}=1)\end{array}$ \\
\hline Diabetes mellitus, $\mathrm{n}$ & 0 & 0 \\
\hline Hypertension, $\mathrm{n}$ & 5 & 10 \\
\hline Angina pectoris, $\mathrm{n}$ & 0 & 4 \\
\hline Chronic drug treatment & $\begin{array}{l}\beta \text {-Blockers }(n=1) \text {, diuretics }(n=3) \text {, anti-hypertensive } \\
\text { drugs }(n=5) \text {, Sintrom }(n=1), \text { methotrexate }(n=1), \\
\text { anti-epileptic drugs }(n=3) \text {, anti-asthmatic drugs }(n=2) \text {, } \\
\text { prednisone }(n=1) \text {, Flolan }(n=1) \text {, corticosteroids }(n=1)\end{array}$ & $\begin{array}{l}\text { Anti-hypertensive drugs }(\mathrm{n}=10) \\
\beta \text {-blockers }(\mathrm{n}=4) \text {, Ascal }(\mathrm{n}=1) \\
\text { Sintrom }(\mathrm{n}=1) \text {, diuretics }(\mathrm{n}=1) \\
\text { prednisone }(\mathrm{n}=1) \text {, anti-epileptic } \\
\text { drugs }(\mathrm{n}=1) \text {, statins }(\mathrm{n}=2)\end{array}$ \\
\hline
\end{tabular}

$\mathrm{AMI}=$ Acute myocardial infarction; $\mathrm{CVA}=$ cerebrovascular accident; $\mathrm{DC}=$ decompensation cordis; $\mathrm{MOF}=$ multiple organ failure; $\mathrm{PHT}=$ pulmonary hypertension; RI = respiratory insufficiency.

in other vascular territories [8-14]. In a previous study, however, we have found evidence for pre-existing accumulations of $\mathrm{N}^{\varepsilon}$-(carboxymethyl)lysine (CML), an advanced glycation end product (AGE), in intramyocardial small arteries in patients with AMI but without diabetes mellitus (DM) that was not related to stenosis of epicardial coronary arteries [15]. These results suppose that pre-existing aberrations in the intramyocardial (micro)vasculature may contribute to the induction of AMI as well.

DM is also a major risk factor for coronary artery disease and coronary artery events $[16,17]$, and it is related to the formation of AGEs [18] resulting in vascular stiffening [19]. In a former study, we showed accumulation of the AGE CML in intramyocardial small arteries in patients with DM [20]. It is known that high levels of AGE can cause increased thickening of the basement membrane (BM) in the diabetic kidney probably caused by the accumulation of plasma proteins or structural proteins, which eventually causes dysfunction of the filtration process [21, 22]. In line with this, BM thickness of capillaries was found to be significantly increased in endomyocardial biopsy specimens in patients with DM compared to control patients [23]. However, to our knowledge, a putative relationship between BM thickness of intramyocar- dial capillaries and AMI independent of DM has not been analyzed. The present study demonstrates that such relation exists.

\section{Materials and Methods}

\section{Human Heart Tissue}

Human hearts were obtained at autopsy $(n=70)$ as soon as possible (at most $24 \mathrm{~h}$ after death). We included 43 patients who died of AMI, of which 1 had an infarction $3 \mathrm{~h}$ before he died by drowning, and 27 control patients who died from causes not related to cardiac disease (table 1). None of these patients had DM. Fifteen patients suffered from hypertension (10 patients with AMI and 5 controls) and were treated with antihypertensive drugs. Four AMI patients had angina pectoris, but the majority of the AMI patients had no cardiovascular history.

Lactate dehydrogenase staining of the heart was used to determine and localize myocardial infarction. Loss of lactate dehydrogenase is indicative of an infarction at least 3-4 h old [24]. All included infarcts in this study were diagnosed using the lactate dehydrogenase staining method.

We only included AMI patients that had an infarction of the left ventricular anterior wall. In AMI patients, tissue from this infarction area was studied, while in controls corresponding areas of the heart were analyzed. In addition, tissue from the right lateral ventricular wall of the heart of each patient was investigated. The included infarctions were determined to be between $3-4 \mathrm{~h}$ and 2 weeks old. This study was approved by and performed 

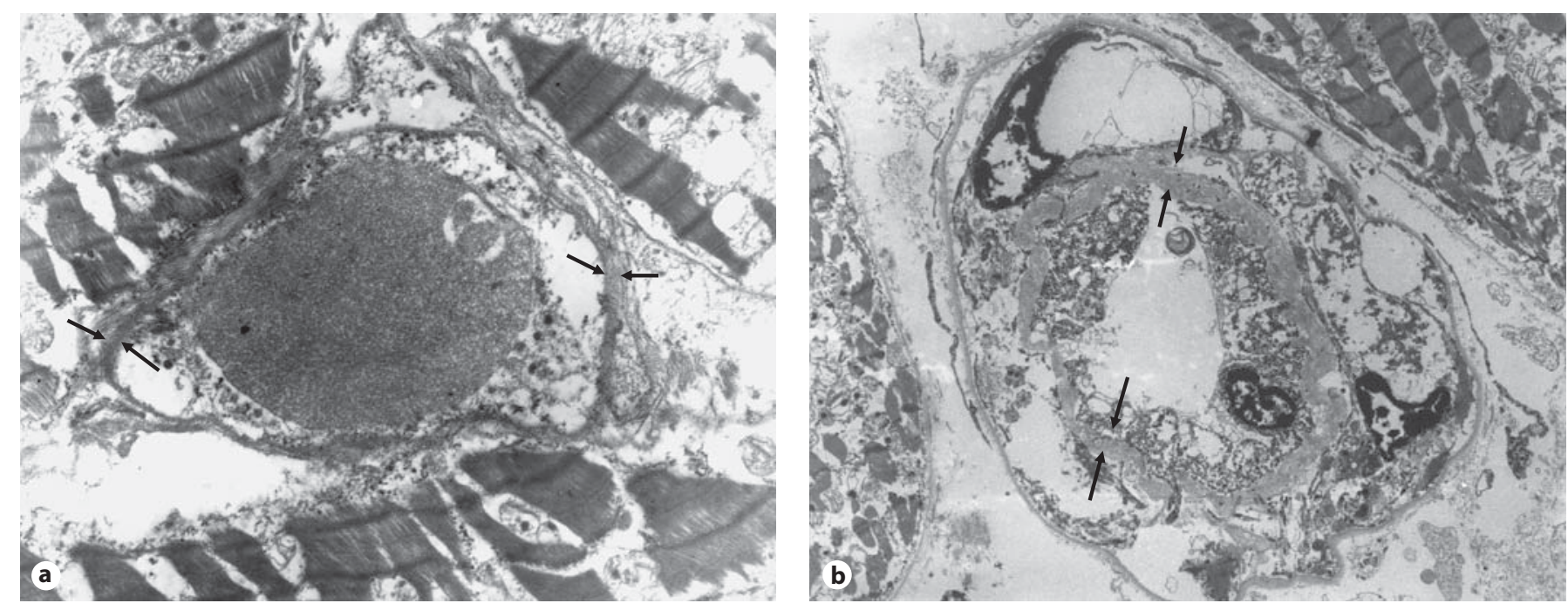

Fig. 1. a Electron microscopic picture of the basement membrane (arrows) in the left ventricle of a control patient. Magnification $\times 15,000$. b Electron microscopic picture of the basement membrane (arrows) in the infarction area within the left ventricle of a patient who died of acute myocardial infarction. Mean thickness is $422 \mathrm{~nm}$. Magnification $\times 6,000$.

according to the guidelines of the ethics committee of the $\mathrm{VU}$ Medical Center, Amsterdam. Use of leftover material after the pathological examination was completed is part of the patient contract in our hospital.

\section{Electron Microscopy}

Heart tissue from all patients was examined using the electron microscope. Heart slides were fixed in $4 \%$ formalin and refixated in $2 \%(\mathrm{v} / \mathrm{v})$ gluteraldehyde for $30 \mathrm{~min}$ and $1.5 \%(\mathrm{w} / \mathrm{v})$ osmium tetraoxide for $10 \mathrm{~min}$, dehydrated with acetone and embedded in Epon 812. Ultra thin sections were collected on 300-mesh Formvar-coated nickel grids. The sections were contracted with uranyl acetate and lead citrate and were examined in a Jeol-1200 EX electron microscope. BM thickness of intramyocardial capillaries was quantified using QPROdit [25]. Per blood vessel, the highest and lowest BM thickness was measured. From each ventricle 10 intramyocardial capillaries were chosen for analysis at random by the electron microscope technician. This technician did not know whether the tissue was from control or AMI patients or from left or right ventricle. The capillaries, therefore, were chosen at random.

\section{Epicardial Coronary Artery}

The left coronary artery (LCA) of control patients and patients with acute myocardial infarction was studied with respect to the percentage of stenosis after microscopic evaluation: grade $0=0 \%$, $1=0-25 \%, 2=25-50 \%, 3=50-75 \%$ and $4=75-100 \%$ stenosis. In each patient, the whole LCA was taken out and was fixated and decalcified and then cut into cross-sections of approximately $5 \mathrm{~mm}$ in length. These cross-sections were examined macroscopically to assess presence of occlusion. After this, 4-7 cross sections with the highest macroscopic level of occlusion were embedded for microscopic histological analysis and occlusion scoring. For the evaluation of a putative correlation between the percentage of LCA stenosis and BM thickness of intramyocardial capillaries, the highest stenosis score of the LCA was used in each patient. In addition, histological atherosclerotic plaque (in)stability was determined within these embedded cross sections of the LCA. Unstable plaques were identified as such in case a thin fibrous cap and/or inflammatory cells at the endothelial layer were found within the LCA. When none of these observations were found, it was identified as a stable plaque [26]. For further analysis, patients were divided into 2 groups, patients with unstable plaques and patients with stable plaques independent of the presence of AMI.

The in vivo Rat AMI Model

Rats were anesthetized intramuscularly with Hypnorm ${ }^{\circledR} /$ Dormicum ${ }^{\circledR}$ (fentanyl + fluanisone $0.5 \mathrm{ml} / \mathrm{kg}$; midazolam $5 \mathrm{mg} / \mathrm{kg}$ ). Hypnorm was from Janssen Pharmaceuticals B.V. (Tilburg, The Netherlands). Dormicum was from Roche Nederland B.V. (Mijdrecht, The Netherlands). The rats were respirated (with room air) using a mechanical ventilator set to 70 breaths $/ \mathrm{min}(7 \mathrm{ml} / \mathrm{kg}$ volume). To induce AMI a ligature (6.0 suture) was placed around the left coronary artery for $30 \mathrm{~min}$, followed by 5 days of reperfusion. Hearts were then excised and prepared as described above (section electron microscopy).

\section{Statistical Analysis}

Statistics were performed using the SPSS statistics program (Windows version 11.5). Because of non-normal distribution of the data, the data were transformed to logarithmic values. Data were analyzed using a 1-way ANOVA, paired t tests and independent $t$ tests. Also post-hoc Bonferroni tests were conducted. Levene's test was used for homogeneity of variances. $p$ values at the 0.05 level were considered significant. Correlation analysis was performed using Pearson's correlation coefficient [27]. We used the following guidelines for determining the strength of 
the correlation: $\mathrm{r}=0.10$ to 0.29 and -0.10 to -0.29 are a weak or small correlation, $\mathrm{r}=0.30$ to 0.49 and -0.30 to -0.49 are a medium correlation and $\mathrm{r}=0.50$ to 1.0 and -0.50 to -1.0 are a strong or large correlation. When using Pearson's correlation, many authors in this area suggest that statistical significance should be reported but ignored, and the focus should be directed at the amount of shared variance. Therefore, we also calculated the coefficient of determination [27].

\section{Results}

In control patients, the mean BM thickness of intramyocardial capillaries in the left ventricle of the heart was $77 \pm 4 \mathrm{~nm}$, varying from 44 to $150 \mathrm{~nm}$ (fig. 1a, 2). In AMI patients (of infarction age varying between $3-4 \mathrm{~h}$ and 2 weeks), the mean BM thickness of the capillaries in the infarction area (left ventricle) was $102 \pm 9 \mathrm{~nm}$ varying from 51 to $422 \mathrm{~nm}$ (fig. 1b, 2). The mean BM thickness of the capillaries in the infarction area was significantly higher than the mean BM thickness in the left ventricle of control patients ( $\mathrm{p}=0.006$; fig. 2 ).

To compare BM thickness in AMI patients between infarcted tissue and non-infarcted tissue, BM thickness of capillaries was determined in the infarction area from the left ventricle and non-infarcted tissue from the right ventricle. In these AMI patients, the mean BM thickness of the capillaries in the infarction area was significantly higher than the mean BM thickness of the right ventricle (86 $\pm 6 \mathrm{~nm}, \mathrm{p}=0.002$; fig. 2 ), while in control patients, the BM thickness did not significantly differ between left $(77 \pm 4 \mathrm{~nm})$ and right ventricle $(84 \pm 7 \mathrm{~nm})$. Also, the BM thickness of the capillaries of the right ventricles in AMI and control patients did not significantly differ.

We also analyzed a putative relation between the age of the infarct and the BM thickness of the infarction area. AMI patients were divided into 3 groups: patients with an infarction less than $6 \mathrm{~h}$ old (this is the early infarction phase, no histological changes can be seen yet), those with an infarction between $6 \mathrm{~h}$ and 5 days old (this is the inflammatory phase of AMI, extra vascular accumulation of neutrophilic granulocytes can be seen) and those with an infarction older than 5 days (this is the remodeling phase of AMI, formation of granulation is found in this phase). Already at AMI $<6 \mathrm{~h}$, a significant increase of BM thickness of the capillaries in the left ventricle was found (107 $\pm 13 \mathrm{~nm}, \mathrm{p}=0.007)$ compared with controls (77 $\pm 4 \mathrm{~nm}$ ), which did not increase in time (AMI older than 5 days: $105 \pm 17 \mathrm{~nm}, \mathrm{p}=0.065$ compared with controls).

Basement Membrane Thickening in AMI

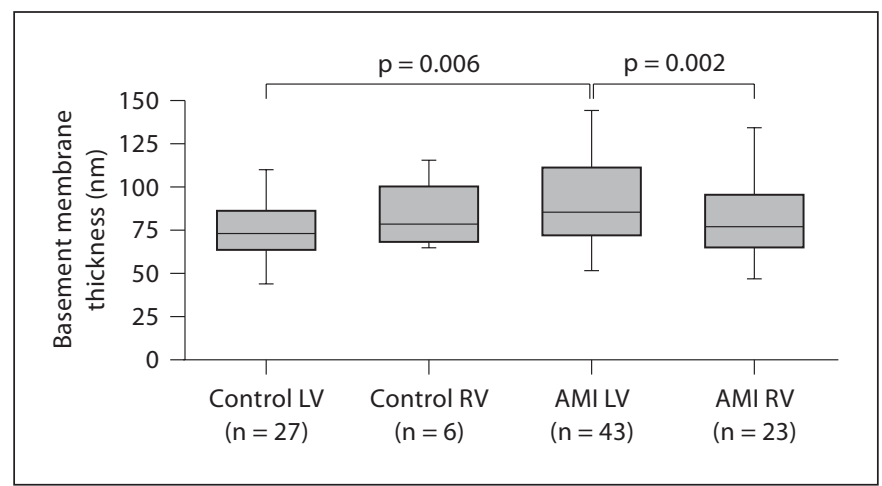

Fig. 2. Box plots of comparison between mean basement membrane thickness of intramyocardial coronary arteries in the left and right ventricle (LV and RV) of control and acute myocardial infarction patients (AMI). The error bars represent 1.5 times the interquartile distance, the boxes represent the lower and upper quartiles, and the black lines within the boxes represent the medians.

A possible relation between the age of the patients and the BM thickness in the left ventricle was also analyzed. AMI and control patients were divided into 3 groups: 0-40, 41-70 and 71-100 years old. In both AMI and control patients, no significant difference in BM thickness of the capillaries was found between the different age groups (not shown).

A putative correlation between the BM thickness of left ventricular intramyocardial capillaries and the degree of stenosis of the epicardial LCA was investigated in 9 control patients and 22 AMI patients. The mean grade score of stenosis in the LCA in control patients was 3.3 (50-75\% stenosis). In patients with AMI, the mean grade score of stenosis in the LCA was also 3.3 (50-75\% stenosis) and thus did not differ from that in control patients. In both control patients and AMI patients, no correlation between the amount of stenosis in the epicardial LCA and $\mathrm{BM}$ thickness of left ventricular intramyocardial capillaries was found $(\mathrm{r}=0.046, \mathrm{p}=0.906$ and $\mathrm{r}=0.001, \mathrm{p}=$ 0.996, respectively). This means that there is no positive linear relation between the amount of stenosis and BM thickness. Also, the coefficient of determination (see 'Materials and Methods') was $0.21 \%$ for control patients and $0.0001 \%$ for AMI patients. This indicates that the variation in BM thickness of intramyocardial capillaries cannot be explained by variations in the amount of stenosis of the epicardial LCA.

A possible relation between BM thickness of left ventricular intramyocardial capillaries and atherosclerotic plaque stability in the LCA was also analyzed in some 


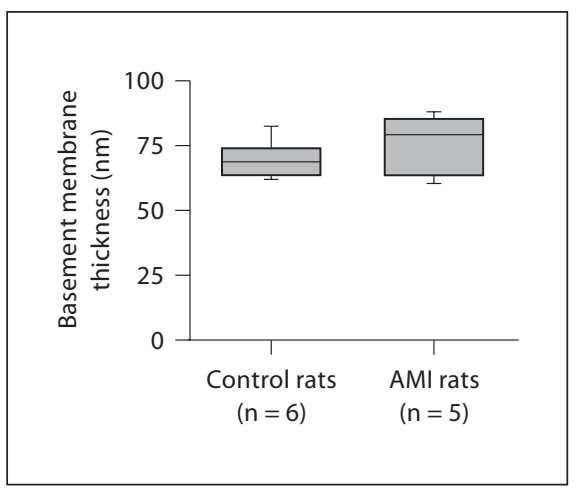

Fig. 3. Box plots of comparison between mean basement membrane thickness of intramyocardial coronary arteries in the left ventricle of control and AMI rats. The error bars represent the standard error of the mean. The error bars represent 1.5 times the interquartile distance, the boxes represent the lower and upper quartiles, and the black lines within the boxes represent the medians.

of the patients included in this study. Five patients showed no signs of unstable plaques, 26 patients did have unstable plaques in the LCA. However, no significant difference in $\mathrm{BM}$ thickness was found between the 2 groups $(\mathrm{p}=0.934)$.

To determine whether AMI can induce BM thickening, the BM thickness of left ventricular intramyocardial capillaries was measured in an in vivo rat AMI model. For this, we used 6 control rats and 5 AMI rats with an infarction of 5 days old. However, we did not find a significant difference in BM thickness between the control and AMI rats in the left ventricle of the heart $(\mathrm{p}=0.343$; fig. 3).

\section{Discussion}

To the best of our knowledge, this is the first paper analyzing BM thickening in intramyocardial capillaries in patients with AMI. We have found that in the infarction area of AMI patients the BM thickness of capillaries was significantly higher compared to corresponding heart tissue in control patients $(102 \pm 9$ vs. $77 \pm 4 \mathrm{~nm}$, $\mathrm{p}=0.006)$ and compared to non-infarcted areas of AMI patients (86 $\pm 6 \mathrm{~nm}, \mathrm{p}=0.002)$.

The BM thickness of intramyocardial capillaries in autopsy hearts of control patients measured here is in accordance with reported BM thickness measurements in endomyocardial biopsies of living patients in non-DM, non-AMI patients, which were, respectively, $80 \mathrm{~nm}$ [28] and $75 \pm 15 \mathrm{~nm}[23]$. This thus indicates that BM thickness is not influenced by changes after death. In another study, no effect of hypertension on BM thickness of capillaries in the heart was found $(67 \pm 8 \mathrm{~nm})$ [23]. We also did not find that this increase in BM thickness was related to the age of the patients, in agreement with previous studies $[28,29]$. However, in patients with DM, but without AMI, increased BM thickness in the heart has been described (between 98 and $153 \pm 48 \mathrm{~nm}$ ) [23, 28]. Therefore, we excluded DM patients from the present study.

Notably, the duration of the infarction was not related to the aberrant BM thickness of intramyocardial capillaries within the infarction area in AMI patients. The BM thickness in the infarction area was already significantly increased in patients with AMI less than $6 \mathrm{~h}$ old and did not increase further with infarct age. In addition, we show in the rat AMI model that AMI followed by 5 days of reperfusion and the concomitant inflammatory reaction did not result in BM thickening. Not a lot is known about the timeframe in which BM thickening can manifest itself. However, in diabetic rat models, BM thickening only became significant after months [30], whereas in another rat model, the earliest extra cellular matrix alterations involved in BM thickening were detected $48 \mathrm{~h}$ after VEGF injection [31]. These data suggest that it is unlikely that a significant increase in BM thickness can manifest itself within $6 \mathrm{~h}$, thereby making it likely that the BM thickening in AMI hearts occurred prior to the $\mathrm{AMI}$ and not as a consequence.

The exact mechanism of basement membrane thickening in patients with AMI is unknown. However, in patients with DM, BM thickening in the kidney is caused by matrix expansion which is due to expression of extracellular matrix components collagen, fibronectin and laminin $[32,33$. Fibrotic factors such as TGF- $\beta 1$ and CTFG were found to play a key role in the BM thickening and increased extracellular matrix in patients with DM [34]. These fibrotic factors are known regulators of exctracellular matrix accumulation and were found to stimulate the production of collagen type IV, fibronectin and laminin in diabetic patients [35-37].

It is unclear how BM thickening of the intramyocardial arteries can contribute to AMI. One of the possibilities is that the thickened basement membrane limits the exchange of oxygen, inducing or aggravating hypoxic stress.

We also found in AMI patients that variation in BM thickness of intramyocardial capillaries was not dependent on the amount of stenosis, nor on atherosclerotic 
plaque stability of the epicardial coronary artery. In addition, in another study (Baidoshvili et al. [15]) we recently found that the advanced glycation end product CML was present in intramyocardial small arteries in patients with AMI. These data suggested that the CML depositions in these intramyocardial small arteries preceded the onset of AMI and were independent of epicardial coronary artery stenosis.

In conclusion, these results suggest that BM thickening and also our previous finding of the formation of AGEs [15] constitute significant changes in the intramyocardial capillaries in patients who develop AMI. Also, these changes are likely to occur prior to the induction of
AMI and are independent of the condition of the epicardial coronary arteries. These data imply that prior to the development of AMI, there are substantial aberrations in the intramyocardial blood vessels. Whether these aberrations are in a causal conjunction with the induction of AMI remains to be established.

\section{Acknowledgments}

This project was financed by the Dutch Forensic Institute (Nederlands Forensisch Instituut), The Hague, The Netherlands. It is project number 34 .

\section{References}

1 Murray CJ, Lopez AD: Alternative projections of mortality and disability by cause 1990-2020: Global Burden of Disease Study. Lancet 1997;349:1498-1504.

2 Murray CJ, Lopez AD: Mortality by cause for eight regions of the world: Global Burden of Disease Study. Lancet 1997;349:1269-1276.

- 3 Theroux P, Fuster V: Acute coronary syndromes: unstable angina and non-Q-wave myocardial infarction. Circulation 1998;97: 1195-1206.

4 Myerburg RJ, Kessler KM, Castellanos A: Sudden cardiac death. Structure, function, and time-dependence of risk. Circulation 1992;85(1 suppl):I2-I10.

- 5 Myerburg RJ, Kessler KM, Castellanos A: Sudden cardiac death: epidemiology, transient risk, and intervention assessment. Ann Intern Med 1993;119:1187-1197.

-6 Myerburg RJ, Interian A Jr, Mitrani RM, Kessler KM, Castellanos A: Frequency of sudden cardiac death and profiles of risk. Am J Cardiol 1997;80:10F-19F.

7 Zipes DP, Wellens HJ: Sudden cardiac death. Circulation 1998;98:2334-2351.

-8 Califf RM, Pieper KS, Lee KL, Van de WF, Simes RJ, Armstrong PW, et al: Prediction of 1 -year survival after thrombolysis for acute myocardial infarction in the global utilization of streptokinase and TPA for occluded coronary arteries trial. Circulation 2000;101: 2231-2238.

9 Gibson CM, Cannon CP, Piana RN, Breall JA, Sharaf B, Flatley M, et al: Angiographic predictors of reocclusion after thrombolysis: results from the Thrombolysis in Myocardial Infarction (TIMI) 4 trial. J Am Coll Cardiol 1995;25:582-589.

10 Gibson CM, Cannon CP, Daley WL, Dodge JT Jr, Alexander B Jr, Marble SJ, et al: TIMI frame count: a quantitative method of assessing coronary artery flow. Circulation 1996;93:879-888.
1 Gibson CM, Murphy S, Menown IB, Sequei- 16 Estep JD, Aguilar D: Diabetes and heart failra RF, Greene R, Van de Werf F, et al: Determinants of coronary blood flow after thrombolytic administration. TIMI Study Group. Thrombolysis in Myocardial Infarction. J Am Coll Cardiol 1999;34:1403-1412.

12 Gibson CM, Cannon CP, Murphy SA, Marble SJ, Barron HV, Braunwald E: Relationship of the TIMI myocardial perfusion grades, flow grades, frame count, and percutaneous coronary intervention to long-term outcomes after thrombolytic administration in acute myocardial infarction. Circulation 2002;105:1909-1913.

13 Lee KL, Woodlief LH, Topol EJ, Weaver WD, Betriu A, Col J, et al: Predictors of 30-day mortality in the era of reperfusion for acute myocardial infarction. Results from an international trial of 41,021 patients. GUSTOI Investigators. Circulation 1995;91:16591668.

14 Lundergan CF, Reiner JS, McCarthy WF, Coyne KS, Califf RM, Ross AM: Clinical predictors of early infarct-related artery patency following thrombolytic therapy: importance of body weight, smoking history, infarct-related artery and choice of thrombolytic regimen: the GUSTO-I experience. Global Utilization of Streptokinase and t-PA for Occluded Coronary Arteries. J Am Coll Cardiol 1998;32:641-647.

15 Baidoshvili A, Krijnen PA, Kupreishvili K, Ciurana C, Bleeker W, Nijmeijer R, et al: $\mathrm{N}$ (varepsilon)-(carboxymethyl)lysine depositions in intramyocardial blood vessels in human and rat acute myocardial infarction: a predictor or reflection of infarction? Arterioscler Thromb Vasc Biol 2006;26:24972503. ure in the post-myocardial infarction patient. Curr Heart Fail Rep 2006;3:164-169.

17 Pajunen P, Koukkunen H, Ketonen M, Jerkkola T, Immonen-Raiha P, Karja-Koskenkari $P$, et al: Myocardial infarction in diabetic and non-diabetic persons with and without prior myocardial infarction: the FINAMI Study. Diabetologia 2005;48:2519-2524.

18 Ulrich P, Cerami A: Protein glycation, diabetes, and aging. Recent Prog Horm Res 2001; 56:1-21. AJ: The role of glycation cross-links in diabetic vascular stiffening. Diabetologia 1996; 39:946-951.

20 Schalkwijk CG, Baidoshvili A, Stehouwer CD, van Hinsbergh VW, Niessen HW. Increased accumulation of the glycoxidation product Nepsilon-(carboxymethyl)lysine in hearts of diabetic patients: generation and characterisation of a monoclonal anti-CML antibody. Biochim Biophys Acta 2004;1636: 82-89.

21 Bucala R, Cerami A: Diabetes; in Gotto AM, Jr, Lenfant C, Catapano AL, Padetti R (eds): Multiple Risk Factors in Cardiovascular Disease: Vascular and Organ Protection. Dordrecht, Kluwer Academic Publishers, 1995, pp 155-163.

22 Makita Z, Radoff S, Rayfield EJ, Yang Z, Skolnik E, Delaney V, et al: Advanced glycosylation end products in patients with diabetic nephropathy. N Engl J Med 1991;325: 836-842.

23 Kawaguchi M, Techigawara M, Ishihata T, Asakura T, Saito F, Maehara K, et al: A comparison of ultrastructural changes on endomyocardial biopsy specimens obtained from patients with diabetes mellitus with and without hypertension. Heart Vessels 1997; 12:267-274.
19 Sims TJ, Rasmussen LM, Oxlund H, Bailey 
24 Becker AE, Anderson RH: Cardiac Pathology. An Integrated Text and Colour Atlas. Edinburgh, Churchill Livingstone, 1983, p 17.

25 Vermeulen EG, Niessen HW, Bogels M, Stehouwer CD, Rauwerda JA, van Hinsbergh VW: Decreased smooth muscle cell/extracellular matrix ratio of media of femoral artery in patients with atherosclerosis and hyperhomocysteinemia. Arterioscler Thromb Vasc Biol 2001;21:573-577.

-26 Lendon CL, Davies MJ, Born GV, Richardson PD: Atherosclerotic plaque caps are locally weakened when macrophages density is increased. Atherosclerosis 1991;87:87-90.

27 Pallant J: SPSS Survival Manual. A step by step guide to data analysis using SPSS for windows (version 12), ed 2. Maidenhead, Open University Press, 2005, pp 121-127.

28 Fischer VW, Barner HB, Leskiw ML: Capillary basal laminar thickness in diabetic human myocardium. Diabetes 1979;28:713719 .
29 Kilo C, Vogler N, Williamson JR: Muscle capillary basement membrane changes related to aging and to diabetes mellitus. Diabetes 1972;21:881-905.

30 Fluckiger W, Perrin IV, Rossi GL: Morphometric studies on retinal microangiopathy and myocardiopathy in hypertensive rats (SHR) with induced diabetes. Virchows Arch B Cell Pathol Incl Mol Pathol 1984;47:7994.

31 Kuiper EJ, Hughes JM, Van Geest RJ, Vogels IM, Goldschmeding R, Van Noorden CJ, et al: Effect of VEGF-A on expression of profibrotic growth factor and extracellular matrix genes in the retina. Invest Ophthalmol Vis Sci 2007;48:4267-4276.

32 Bruneval P, Foidart JM, Nochy D, Camilleri JP, Bariety J: Glomerular matrix proteins in nodular glomerulosclerosis in association with light chain deposition disease and diabetes mellitus. Hum Pathol 1985;16:477484.
3 Scheinman JI, Steffes MW, Brown DM, Mauer SM: The immunohistopathology of glomerular antigens. III. Increased mesangial actomyosin in experimental diabetes in the rat. Diabetes 1978;27:632-637.

34 Sharma K, Ziyadeh FN: Hyperglycemia and diabetic kidney disease. The case for transforming growth factor-beta as a key mediator. Diabetes 1995;44:1139-1146.

- 35 MacKay K, Striker LJ, Stauffer JW, Doi T, Agodoa LY, Striker GE: Transforming growth factor-beta. Murine glomerular receptors and responses of isolated glomerular cells. J Clin Invest 1989;83:1160-1167.

36 Nakamura T, Miller D, Ruoslahti E, Border WA: Production of extracellular matrix by glomerular epithelial cells is regulated by transforming growth factor-beta 1 . Kidney Int 1992;41:1213-1221.

37 Suzuki S, Ebihara I, Tomino Y, Koide H: Transcriptional activation of matrix genes by transforming growth factor beta 1 in mesangial cells. Exp Nephrol 1993;1:229-237. 